\title{
Effect of Iron Phase on Calcination and Properties of Barium Calcium Sulfoaluminate Cement
}

\author{
Jun Chang ${ }^{1}$, Jixin Zhang ${ }^{1}$, Yanchen Yuan ${ }^{2, *}$ and Kai Cui ${ }^{1, *}$ \\ 1 School of Civil Engineering, Dalian University of Technology, Dalian 116024, China; \\ mlchang@dlut.edu.cn (J.C.); ZJXin@mail.dlut.edu.cn (J.Z.) \\ 2 School of Materials Science and Engineering, University of Jinan, Jinan 250022, China \\ * Correspondence: yuancyan66@163.com (Y.Y.); jiancaick@mail.dlut.edu.cn (K.C.)
}

check for updates

Citation: Chang, J.; Zhang, J.; Yuan, Y.; Cui, K. Effect of Iron Phase on Calcination and Properties of Barium Calcium Sulfoaluminate Cement. Materials 2021, 14, 5813. https:// doi.org/10.3390/ma14195813

Academic Editor: Fernando Pacheco Torgal

Received: 30 August 2021

Accepted: 25 September 2021

Published: 4 October 2021

Publisher's Note: MDPI stays neutral with regard to jurisdictional claims in published maps and institutional affiliations.

Copyright: (c) 2021 by the authors. Licensee MDPI, Basel, Switzerland. This article is an open access article distributed under the terms and conditions of the Creative Commons Attribution (CC BY) license (https:// creativecommons.org/licenses/by/ $4.0 /)$.

\begin{abstract}
In this paper, the effect of iron phase content on the calcination and properties of clinker and barium calcium sulfoaluminate cement was studied. The compressive strength of the samples was tested and combined with an XRD and SEM-EDS analysis, and the microstructure and composition of the barium calcium sulfoaluminate clinker and hydrated samples were characterized. The results showed that the oval-shaped particles were $C_{2} S$ minerals, and the hexagonal plate-shaped or rhombohedral dodecahedral particles were $\mathrm{C}_{2.75} \mathrm{~B}_{1.25} \mathrm{~A}_{3} \overline{\mathrm{S}}$. The Ba element was mainly distributed in the barium calcium sulfoaluminate region, and some of it was dissolved in $\mathrm{C}_{2} \mathrm{~S}$; the Fe element was distributed between $\mathrm{C}_{2.75} \mathrm{~B}_{1.25} \mathrm{~A}_{3} \overline{\mathrm{S}}$ and $\mathrm{C}_{2} \mathrm{~S}$ crystal grains in the form of an iron phase solid solution, which acted as a solvent. When the iron phase composition was $\mathrm{C}_{4} \mathrm{AF}$ and the iron phase content was $5 \%$, the early hydration and later strength were better, and the compressive strength after curing for 1, 3 and 28 days was 73.2 $\mathrm{MPa}, 97.9 \mathrm{MPa}$ and 106.9 $\mathrm{MPa}$, respectively. A proper amount of the iron phase can reduce the eutectic point of the sintered mature material system, increase the amount of liquid phase, reduce the viscosity of the liquid phase, effectively accelerate the migration of mineral ions and promote the formation and growth of minerals.
\end{abstract}

Keywords: barium calcium sulfoaluminate cement; iron phase content; hydration

\section{Introduction}

The main minerals of calcium barium sulfoaluminate cement are $\mathrm{C}_{2.75} \mathrm{Ba}_{1.25} \overline{\mathrm{S}}$ and $\beta-C_{2} S$. It has the advantages of fast hardening, early strength, anti-corrosion and corrosion resistance, and it plays an important role in special engineering applications [1-6]. In addition, many researchers recognized that the iron phase in cement was a solid solution series with a composition in the range of $\mathrm{C}_{2} \mathrm{~F}-\mathrm{C}_{6} \mathrm{~A}_{2} \mathrm{~F}$. Generally, $\mathrm{C}_{2} \mathrm{~F}, \mathrm{C}_{6} \mathrm{AF}_{2}, \mathrm{C} 4 \mathrm{AF}$ and $\mathrm{C}_{6} \mathrm{~A}_{2} \mathrm{~F}$ are the representative minerals of this series. It has some influence on the cement reactivity. In Portland cement, $\mathrm{C} 4 \mathrm{AF}$ and $\mathrm{C}_{3} \mathrm{~A}$ melt into a liquid phase during the calcination process, which can promote the formation of $\mathrm{C}_{3} \mathrm{~S}$ [7]. Zhu Ming et al. used chemical reagent ingredients to research the formation process and hydration performance of the undoped iron phases $\mathrm{C}_{2} \mathrm{~F}, \mathrm{C}_{6} \mathrm{AF}_{2}, \mathrm{C}_{4} \mathrm{AF}$ and $\mathrm{C}_{6} \mathrm{~A}_{2} \mathrm{~F}$. The results showed that the iron phase always diffused and replaced the $\mathrm{C}_{2} \mathrm{~F}$ lattice through $\mathrm{Al}^{+3}$ ions. When the different components were not doped, the synthesis of the iron phase became difficult with the increase of the $\mathrm{Al} / \mathrm{Fe}$ ratio. The iron phase represented by $\mathrm{C}_{4} \mathrm{AF}$ not only has good wear resistance and corrosion resistance, but also has good mechanical properties [8]. Wang Yanmou et al. studied the formation mechanism of the iron phase in ferro-aluminate cement and clarified the formation mechanism of the four representative minerals $\mathrm{C}_{2} \mathrm{~F}$, $\mathrm{C}_{6} \mathrm{AF}_{2}, \mathrm{C}_{4} \mathrm{AF}$ and $\mathrm{C}_{6} \mathrm{~A}_{2} \mathrm{~F}$ [9].

On this basis, the formation process of the iron phase in ferro-aluminate cement clinker was studied. The results showed that the composition of the iron phase was close to $\mathrm{C}_{6} \mathrm{AF}_{2}$; the formation of the iron phase was due to the $\mathrm{Al}^{3+}$ into the $\mathrm{C}_{2} \mathrm{~F}$ lattice. The final composition of the iron phase depended on the $\mathrm{Al} / \mathrm{Fe}$ atomic weight ratio of 
the raw material and the sintering temperature [10]. Huang Yeping et al. used XRD, TG and other test methods to study the influence of $\mathrm{Fe}_{2} \mathrm{O}_{3}$ on the formation of $\mathrm{C}_{4} \mathrm{~A}_{3} \overline{\mathrm{S}}$. Studies have shown that the addition of $\mathrm{Fe}_{2} \mathrm{O}_{3}$ can promote the absorption of $\mathrm{f}-\mathrm{CaO}$ in the clinker, increase the amount of the liquid phase and improve the burnability of $\mathrm{C}_{4} \mathrm{~A}_{3} \overline{\mathrm{S}}$ [11]. $\mathrm{Li}$ Yanjun et al. studied the influence of $\mathrm{Fe}_{2} \mathrm{O}_{3}$ on the formation of alite-sulfoaluminate cement clinker minerals with pure chemical reagent ingredients. The results showed that when calcined at a low temperature, $\mathrm{Fe}_{2} \mathrm{O}_{3}$ was not conducive to the absorption of $\mathrm{f}-\mathrm{CaO}$ in the system; a certain amount of $\mathrm{Fe}_{2} \mathrm{O}_{3}$ can promote the formation of $\mathrm{C}_{3} \mathrm{~S}$ and $\mathrm{C}_{4} \mathrm{~A}_{3} \overline{\mathrm{S}}$ at a high temperature, which was conducive to their coexistence in the clinker. Furthermore, when the content of $\mathrm{Fe}_{2} \mathrm{O}_{3}$ was higher, it would hinder the formation of $\mathrm{C}_{3} \mathrm{~S}$ and reduce the content of $\mathrm{C}_{4} \mathrm{~A}_{3} \overline{\mathrm{S}}$ [12].

Previous studies on sulfoaluminate cement have shown that the iron phase played an important role in the firing process of sulfoaluminate cement, which has attracted more and more attention. A lot of research has been conducted on sulfoaluminate cement [13-17]. However, there are few studies on the influence of iron phase content on the calcination and performance of barium calcium sulfoaluminate cement. Therefore, it is of great significance to study the iron phase in barium calcium sulfoaluminate cement and obtain the law and understanding of the influence of iron phase content on barium calcium sulfoaluminate cement. The research results have important theoretical value for enriching and improving the barium calcium sulfoaluminate cement system, have important guiding and practical significance for the selection of raw materials and production practices and provide a reasonable and effective method for studying the iron phase [18-21].

\section{Experiment}

\subsection{Materials}

The analytical pure chemical reagents including $\mathrm{CaCO}_{3}, \mathrm{BaCO}_{3}, \mathrm{Al}_{2} \mathrm{O}_{3}, \mathrm{SiO}_{2}, \mathrm{Fe}_{2} \mathrm{O}_{3}$ and $\mathrm{CaSO}_{4} \cdot 2 \mathrm{H}_{2} \mathrm{O}$ were used in the experiment, produced by Tianjin Guangcheng Chemical Reagent Co., Ltd, Tianjin, China. The mineral composition of the designed clinker was $\mathrm{C}_{2.75} \mathrm{~B}_{1.25} \mathrm{~A}_{3} \overline{\mathrm{S}}, \mathrm{C}_{2} \mathrm{~S}$ and the iron phase [22-25]. The composition of each group is shown in Table 1. The weighed raw meal was mixed with water and put into the steel tank of the planetary mill for stirring, then the mixed raw material was put into a blast box for drying. Finally, the raw material was pressed into a $60 \mathrm{~mm} \times 10 \mathrm{~mm}$ test cake and put it into a blast drying box to keep it warm for $1 \mathrm{~h}$. The samples were put into a high-temperature furnace for calcination, the temperature was raised to $1350{ }^{\circ} \mathrm{C}$ with a heating rate of $5{ }^{\circ} \mathrm{C} / \mathrm{min}$ and kept warm for $2 \mathrm{~h}$ and then the samples were taken out and cooled to room temperature quickly [26-31].

Table 1. Mineral composition of clinkers.

\begin{tabular}{cccc}
\hline \multirow{2}{*}{ Number } & \multicolumn{3}{c}{ The Content of Mineral Composition/\% } \\
& $\mathbf{C}_{\mathbf{2 . 7 5}} \mathbf{B a}_{\mathbf{1 . 2 5}} \mathbf{A}_{\mathbf{3}} \overline{\mathbf{S}}$ & $\mathbf{C}_{\mathbf{2}} \mathbf{S}$ & $\mathbf{C}_{\mathbf{4}} \mathbf{A F}$ \\
\hline CAF0 & 60 & 40 & 0 \\
CAF1 & 60 & 39 & 1 \\
CAF2 & 60 & 37 & 3 \\
CAF3 & 60 & 35 & 5 \\
CAF4 & 60 & 33 & 7 \\
CAF5 & 60 & 31 & 9 \\
CAF6 & 60 & 28 & 12 \\
CAF7 & 60 & 25 & 15 \\
\hline
\end{tabular}

\subsection{Experimental Methods}

The calcined cement clinker was grounded and the fineness was less than 200 mesh sieves, and the sieve residue was within the range of $1-5 \%$ (74 $\mu \mathrm{m}$ sieve opening). Then, the grounded cement clinker was mixed with water (the water to cement ratio was 0.3 ) stirred and vibrated for $3 \mathrm{~min}$, and paste was poured into a mold $\left(2 \times 2 \times 2 \mathrm{~cm}^{3}\right)$ and 
placed in a standard curing at a room temperature of $20^{\circ} \mathrm{C}$ for 1,3 and 28 days. Finally, the mechanical properties of cement were measured after 1 day, 3 day and 28 days of curing ages according to standard ISO 679:2009, the 6 samples were tested for per age, the error bars were calculated as the standard deviation and the composition structure was analyzed. The compressive strength of each sample was carried out with a loading rate of $2400 \mathrm{~N} / \mathrm{s} \pm 200 \mathrm{~N} / \mathrm{s}$.

The QM-4L planetary ball mill (Nanjing Nanda Instrument Factory, Nanjing, China) was used, the ZB101-1 electric blast box (Zibo Instrument Factory, Zibo, China) was used and the box-type resistance furnace (Longkou Electric Furnace Factory, Yantai, China) was used. A WDW-200E microcomputer-controlled electronic type universal testing machine (Jinan Testing Machine Factory, Jinan, China) with a loading rate of $60 \mathrm{~N} / \mathrm{s}$ and an X-ray diffractometer (XRF, Shimadzu, Kyoto, Japan) were used to detect the composition of the cement, and XRD (XRD, Brooke, Germany) measurements were performed using a D8 Advance $\mathrm{X}$-ray diffractometer with $\mathrm{Cu}$ target $\left(\mathrm{Cu} \mathrm{K} \alpha_{1,2}\right.$ radiation). The working voltage and working current are $40 \mathrm{kV}$ and $40 \mathrm{~mA}$, respectively, the test range is $5-80^{\circ}$

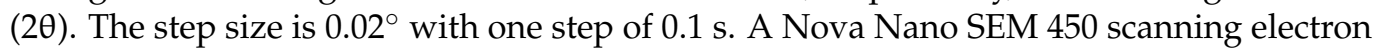
microscope (SEM, FEI, Hillsboro, OR, USA) was used to observe the morphology of the cement. The sample was sprayed with gold for $60 \mathrm{~s}$, the pressure was $30 \mathrm{~Pa}$, the current was $15 \mathrm{~mA}$, the electron beam spot was 3 and the acceleration voltage was $3 \mathrm{kV}$.

\section{Results and Analysis}

\subsection{Effect of $C_{4} A F$ Content on Barium Calcium Sulfoaluminate Cement \\ 3.1.1. Mechanical Properties}

It can be seen from Table 2 and Figure 1 that when the iron phase content was lower than $1 \%$, the compressive strength was higher. This was due to the high content of $\mathrm{C}_{2.75} \mathrm{~B}_{1.25} \mathrm{~A}_{3} \overline{\mathrm{S}}$ and $\mathrm{C}_{2} \mathrm{~S}$ in the mineral composition of the clinker calcination at $1350{ }^{\circ} \mathrm{C}$. The hydration of barium calcium sulfoaluminate provided early strength, and the hydration of $\mathrm{C}_{2} \mathrm{~S}$ mainly provided later strength. Although it could provide higher strength when the iron phase content was relatively low, in practice, when the iron phase content was low, there were fewer flux minerals during the formation of minerals, which was not conducive to the migration of ions in the minerals during the clinker calcination process.

With the increase of the iron phase, the compressive showed a decreased trend, but when the content of the iron phase reached $15 \%$, the early strength and later strength had an improvement, and the compressive strength of 3 days and 28 days were $76.2 \mathrm{MPa}$ and 102.5 MPa, respectively. However, part of the samples melted, which may bring certain difficulties to the kiln operation in the actual production. A proper content of the iron phase can reduce the calcination temperature, reduce the viscosity of the liquid phase, increase the amount of the liquid phase and promote the formation of minerals. When the content of the iron phase was $5 \%$, the compressive strength was optimal. The compressive strength of 1,3 and 28 days were $73.2 \mathrm{MPa}, 97.9 \mathrm{MPa}$ and $106.9 \mathrm{MPa}$, respectively.

Table 2. Compressive strength of clinkers (MPa).

\begin{tabular}{cccc}
\hline Number & 1 Day & 3 Days & 28 Days \\
\hline CAF0 & 65.5 & 71.2 & 96.5 \\
CAF1 & 77.2 & 87.4 & 105.6 \\
CAF2 & 68.4 & 67.5 & 64.5 \\
CAF3 & 73.2 & 97.9 & 106.9 \\
CAF4 & 70.8 & 66.5 & 100.6 \\
CAF5 & 71.4 & 87.6 & 93.1 \\
CAF6 & 70.2 & 72.3 & 98.2 \\
CAF7 & 74.3 & 76.2 & 102.5 \\
\hline
\end{tabular}




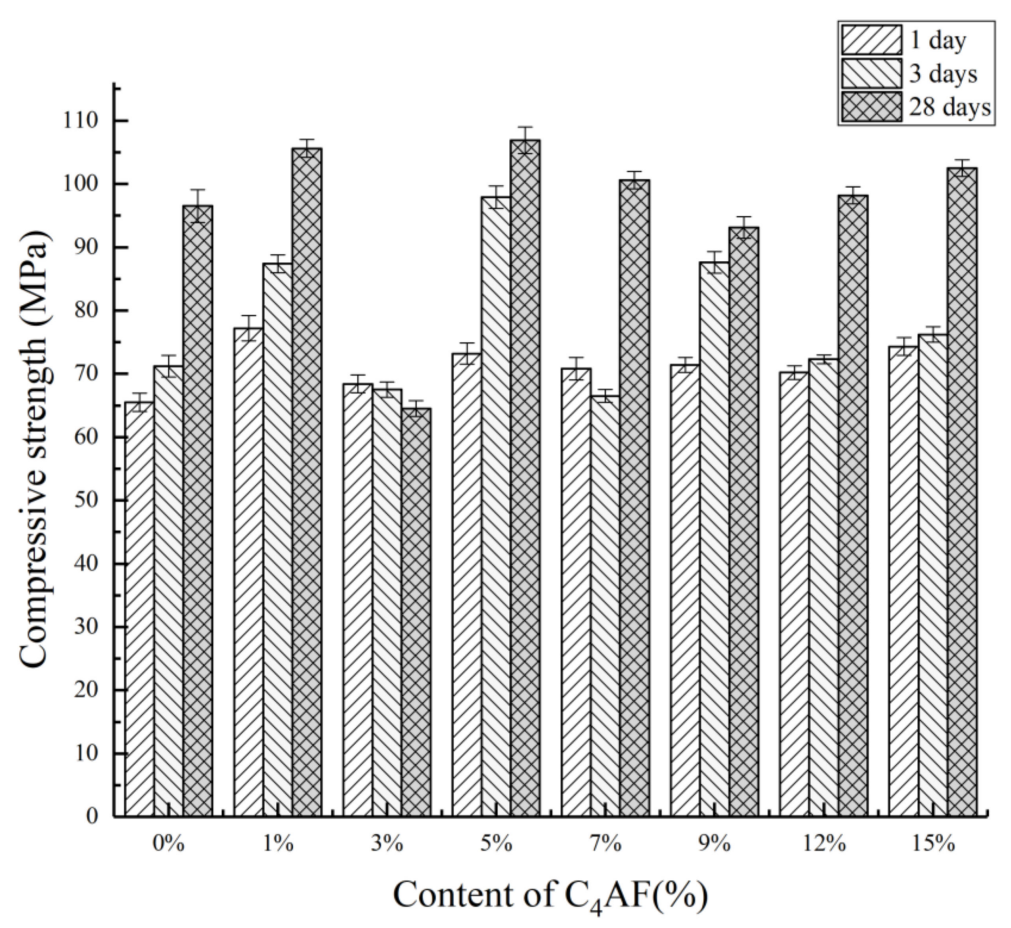

Figure 1. Compressive strength of the different $\mathrm{C}_{4} \mathrm{AF}$ content of the clinker at $1350{ }^{\circ} \mathrm{C}$.

\subsubsection{XRD Analysis}

It can be seen from Figure 2 that the main minerals of the calcium barium sulfoaluminate cement clinker was $C_{2.75} B_{1.25} A_{3} \bar{S}$ and $\beta-C_{2} S$, and there were fewer impurity peaks and the diffraction peak was sharp, indicating that the mineral crystals were well developed. It can be found that the intensity of the diffraction peaks gradually increased with the increase of the $\mathrm{C}_{4} \mathrm{AF}$ content: when the content of $\mathrm{C}_{4} \mathrm{AF}$ was $5 \%$, the first and second diffraction peaks of $\mathrm{C}_{2.75} \mathrm{~B}_{1.25} \mathrm{~A}_{3} \overline{\mathrm{S}}$ were sharper and the diffraction peak intensity was higher. This showed that there were more of $\mathrm{C}_{2.75} \mathrm{~B}_{1.25} \mathrm{~A}_{3} \overline{\mathrm{S}}$ formed in the clinker, and the crystal crystallization condition was good. The diffraction peak of $\mathrm{C}_{4} \mathrm{AF}$ was not obvious due to the diffraction peak of $\mathrm{C}_{4} \mathrm{AF}$ and the diffraction peak of $\mathrm{C}_{2} \mathrm{~S}$ was partially overlapped.

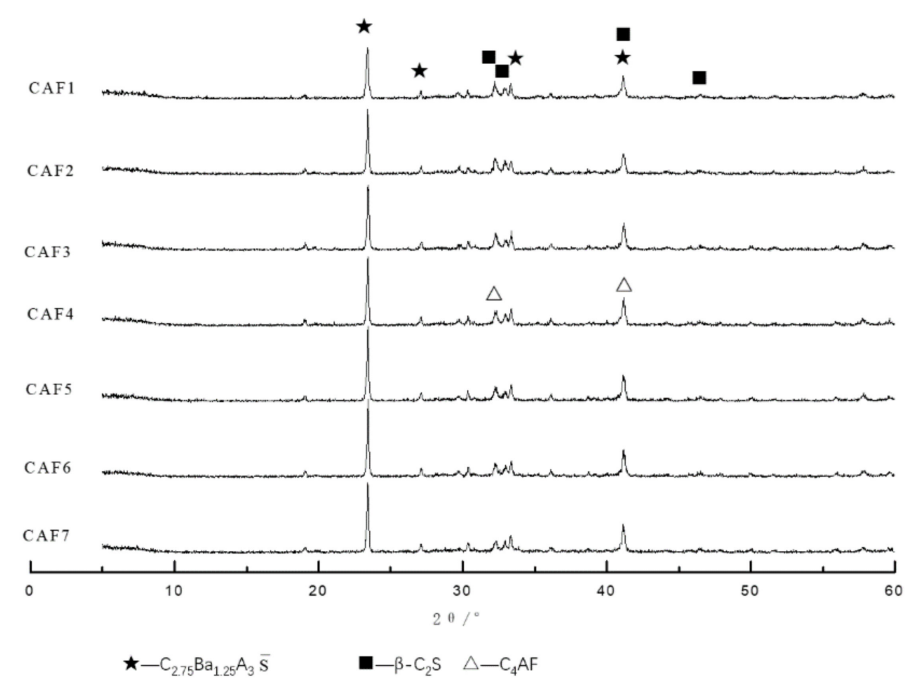

Figure 2. XRD patterns of different clinkers at $1350{ }^{\circ} \mathrm{C}$. 


\subsubsection{SEM Observation}

Figure 3 is the SEM-EDS of the barium calcium sulfoaluminate cement clinker with $1 \% \mathrm{C}_{4} \mathrm{AF}$ content. It can be seen that the clinker had less liquid phase, the grain boundaries between the particles were blurred and the structure was looser. Combined with the EDS at Figure 3c, it can be concluded that the oval granular mineral at this point was $\beta-C_{2} S$, and the crystal grain size was about $10 \mu \mathrm{m}$. Combined with the EDS at Figure $3 \mathrm{~d}$, a large number of small rhombohedral particles can be observed. These particles were $\mathrm{C}_{2.75} \mathrm{~B}_{1.25} \mathrm{~A}_{3} \overline{\mathrm{S}}$, and the grain size was about $3-5 \mu \mathrm{m}$. Because the liquid phase was lower in the sintering process, it was not conducive to the migration of mineral ions during the clinker calcination process, which would affect the formation and development $[29,31]$.
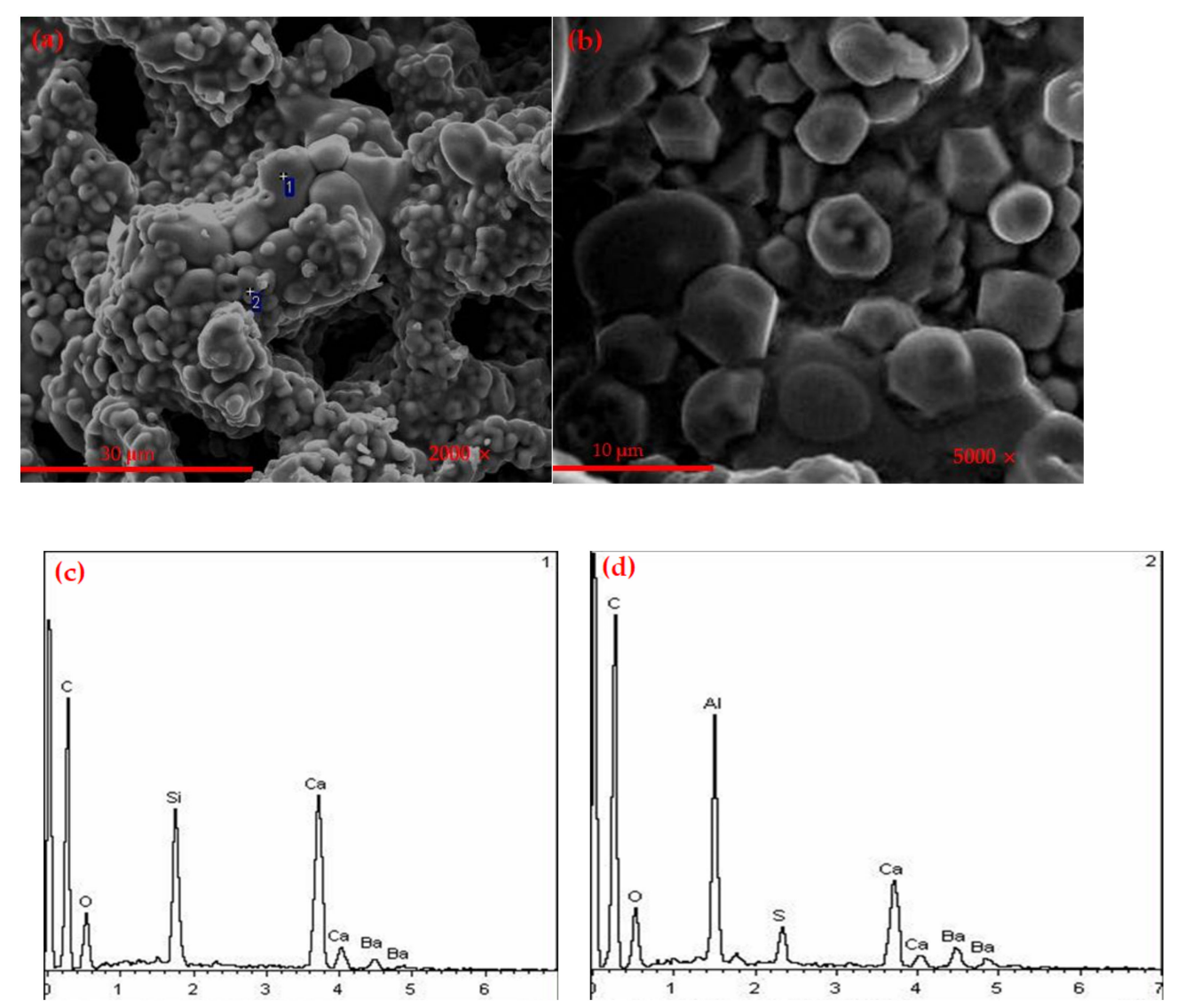

Figure 3. SEM-EDS micrographs of (a,b) $\mathrm{CAF}_{1}$ clinker, (c) 1-EDS, (d) 2-EDS.

Figure 4 is the SEM-EDS of the barium calcium sulfoaluminate cement clinker with $5 \% \mathrm{C}_{4} \mathrm{AF}$ content. It can be seen that the minerals were in an aggregated state, with a certain liquid phase and the grain boundaries between particles were clearer. The crystal size was ranging from 10 to $20 \mu \mathrm{m}$. Combined with the SEM-EDS of 2-point, the mineral was $\beta-C_{2} S$. There were a large number of small hexagonal particles, with a crystal size of 3-5 $\mu \mathrm{m}$. Combined with the SEM-EDS of 4-point, the mineral was $\mathrm{C}_{275} \mathrm{~B}_{1.25} \mathrm{~A}_{3} \overline{\mathrm{S}}$. Part of the irregular melting phase can be seen at the interface of these two minerals. Combined with the SEM-EDS of 3-point, it was a liquid phase mineral containing iron. 


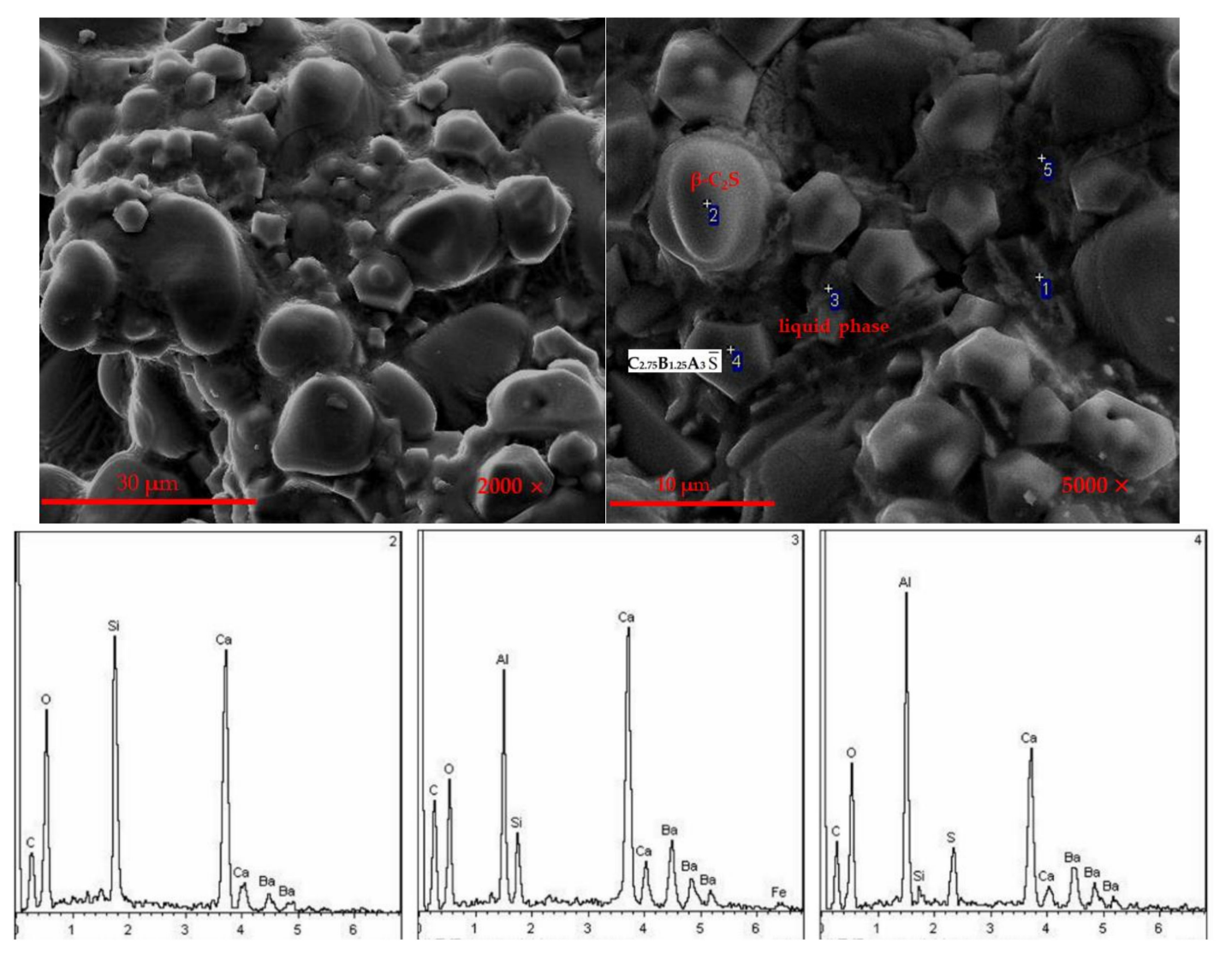

Figure 4. SEM-EDS photographs of $\mathrm{CAF}_{3}$ clinker.

Figure 5 is the SEM-EDS of the barium calcium sulfoaluminate cement clinker with $9 \% \mathrm{C}_{4} \mathrm{AF}$ content. It can be seen that the mineral structure was loose, the grain boundary was not clear and the liquid phase was higher than CAF1 and CAF3. Combining the EDS at 1, 2, and 3-points, it can be seen that the egg-shaped particles were $\beta-C_{2} S$, and the hexagonal plate-shaped mineral particles were $C_{2.75} B_{1.25} A_{3} \bar{S}$. It can be seen that some of the hexagonal flake-shaped particles were irregular morphology. This was because the iron phase content was high, and when the calcination temperature was $1350{ }^{\circ} \mathrm{C}$, the eutectic point of the mineral was lower, which made the barium calcium sulfoaluminate mineral partially dissolved.

The Ba element was mainly distributed in the hexagonal plate-shaped barium calcium sulfoaluminate mineral area, the $\mathrm{Ba}^{2+}$ replaced $\mathrm{Ca}^{2+}$ and formed barium calcium sulfoaluminate mineral; however, there was also a part of the Ba element distributed in the egg-shaped dicalcium silicate area. $\mathrm{Ba}^{2+}$ were solid-dissolved into the $\mathrm{C}_{2} \mathrm{~S}$ minerals, which can effectively activate the crystal lattice and increase the activity of $C_{2} S$, which was one of the reasons for the higher strength of this series of cements. Fe elements were distributed throughout the viewing area. During the formation of minerals, iron-aluminum phases were formed, and iron phases were distributed in the minerals between the crystal grains of $\mathrm{C}_{2.75} \mathrm{~B}_{1.25} \mathrm{~A}_{3} \overline{\mathrm{S}}$ and $\mathrm{C}_{2} \mathrm{~S}$. At the same time, some iron may be dissolved in the $\mathrm{C}_{2.75} \mathrm{~B}_{1.25} \mathrm{~A}_{3} \overline{\mathrm{S}}$ and $\mathrm{C}_{2} \mathrm{~S}$ minerals. 

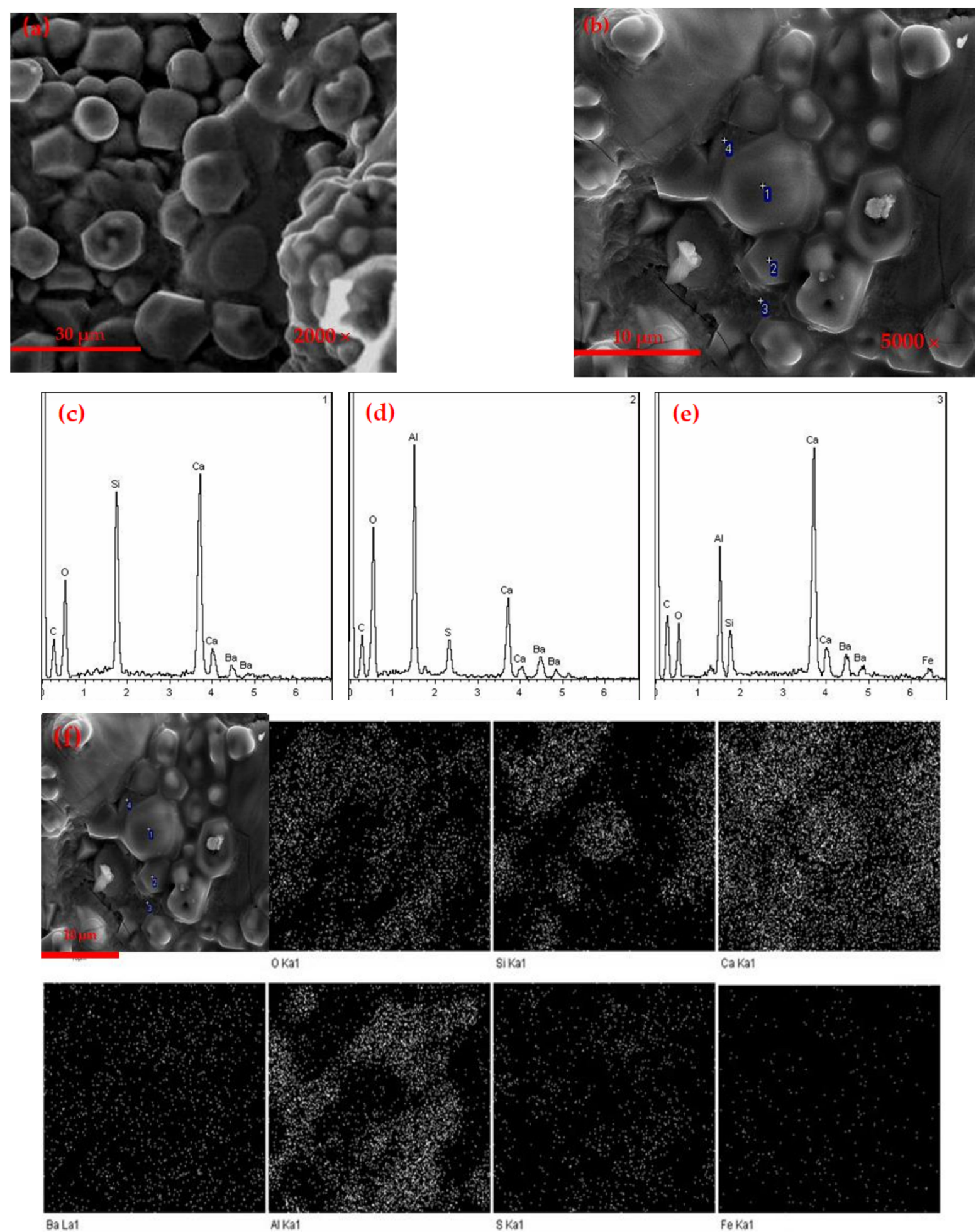

Figure 5. SEM-EDS photographs of (a,b) CAF5 clinker, (c) 1-EDS, (d) 2-EDS, (e) 3-EDS, (f) scanning photograph of the cement clinker CAF5.

\subsection{XRD and SEM Analysis of Hydration Samples}

3.2.1. XRD Analysis of Hydrated Samples

The XRD patterns of CAF1, CAF3, and CAF5 at different curing times are shown in

Figures 6-8. It can be seen from Figure 6 that compared to the diffraction peaks of the 
cement clinker, the diffraction peaks of the barium calcium sulfoaluminate minerals were reduced, indicating that the early hydration rate of barium calcium sulfoaluminate minerals was very fast, which provided early strength. Comparing the XRD pattern of 3 days and 28 days hydration products, there was basically no obvious change, indicating that the hydration degree of minerals at 3 days was already very high, and the hydration was basically completed at 28 days. $\mathrm{C}_{2} \mathrm{~S}$ had a small amount of hydration, the early hydration speed was relatively slow, and the diffraction peaks were not changed obviously along with the curing time. This feature provided a guarantee for the later strength growth of this kind of cement. The diffraction peaks of $\mathrm{CAH}_{10}$ gradually increased along with the curing time. The main hydration products were $\mathrm{BaSO}_{4}, \mathrm{CAH}_{10}$ and a small amount of $\mathrm{C}_{3} \mathrm{AH}_{6}$, and there were also some $\mathrm{C}_{2} \mathrm{~S}$ and $\mathrm{C}_{2.75} \mathrm{Ba}_{1.25} \mathrm{~A}_{3} \overline{\mathrm{S}}$ that had not been hydrated.

Figure 7 is the XRD pattern of the CAF3 (5\%) clinker and hydrated samples at different curing times. It can be seen that the main hydration products were $\mathrm{BaSO}_{4}, \mathrm{CAH}_{10}$ and $\mathrm{C}_{3} \mathrm{AH}_{6}$. Compared with the XRD patterns of the clinker and the hydration products at 1,3 and 28 days, it can be seen that the XRD pattern of the CAF3 hydrated sample was similar to that of CAF1.

Figure 8 is the XRD pattern of the CAF5 (9\%) clinker and hydrated samples at different curing ages. It can be seen that the main hydration products were $\mathrm{BaSO}_{4}, \mathrm{CAH}_{10}$ and $\mathrm{C}_{3} \mathrm{AH}_{6}$, and the diffraction peaks of $\mathrm{CAH}_{10}$ increased along with the curing time. Compared with the XRD patterns of the clinker and hydrated samples for 1, 3 and 28 days, it can be seen that the XRD patterns of the CAF5 hydrated samples were similar to CAF1 and CAF3.

Figure 9 is the XRD patterns of CAF1, CAF3 and CAF5 at curing for $28 \mathrm{~d}$. It can be seen that the main hydration products of the samples were $\mathrm{BaSO}_{4}, \mathrm{CAH}_{10}$ and unhydrated $\mathrm{C}_{2} \mathrm{~S}$ and $\mathrm{C}_{2.75} \mathrm{~B}_{1.25} \mathrm{~A}_{3} \overline{\mathrm{S}}$. When CAF1 was curing for 28 days, the peak value of $\mathrm{CAH}_{10}$ in the hydrated product was higher than the other two. This was also one of the reasons for the higher strength of CAF1.

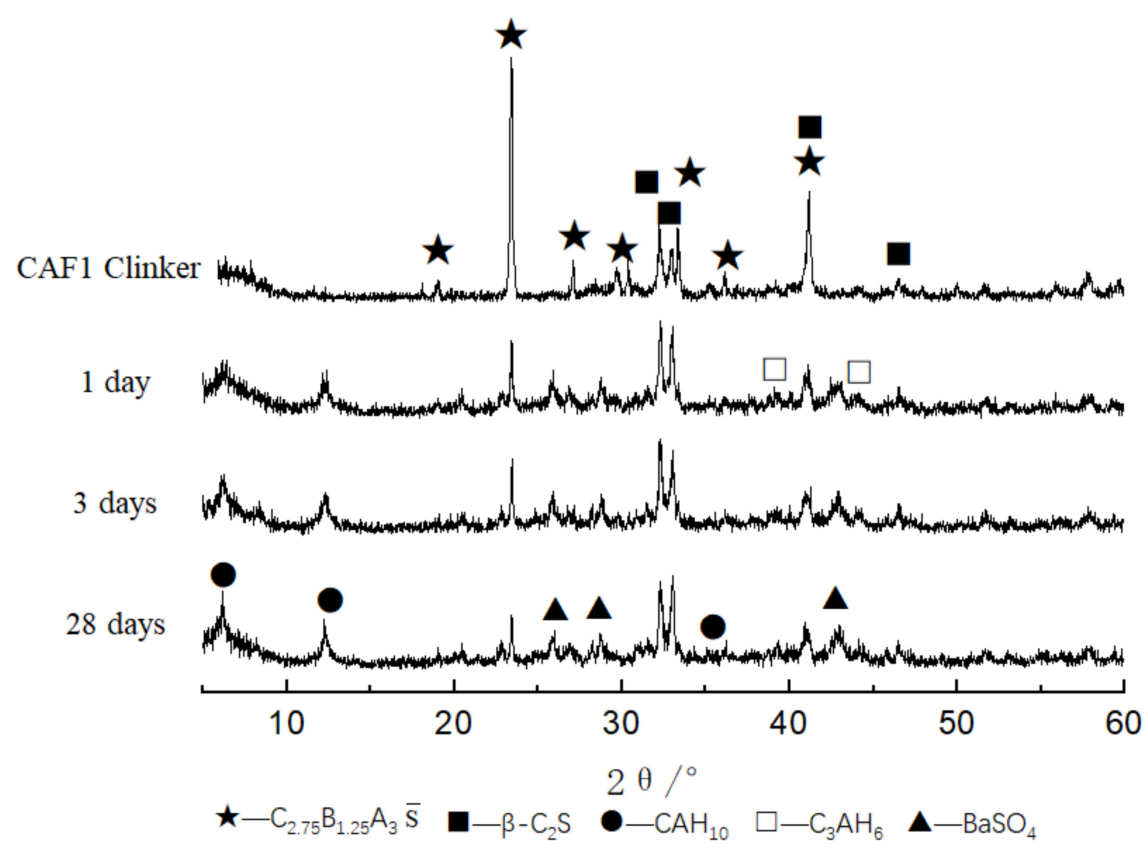

Figure 6. XRD patterns of CAF1 at different curing times. 


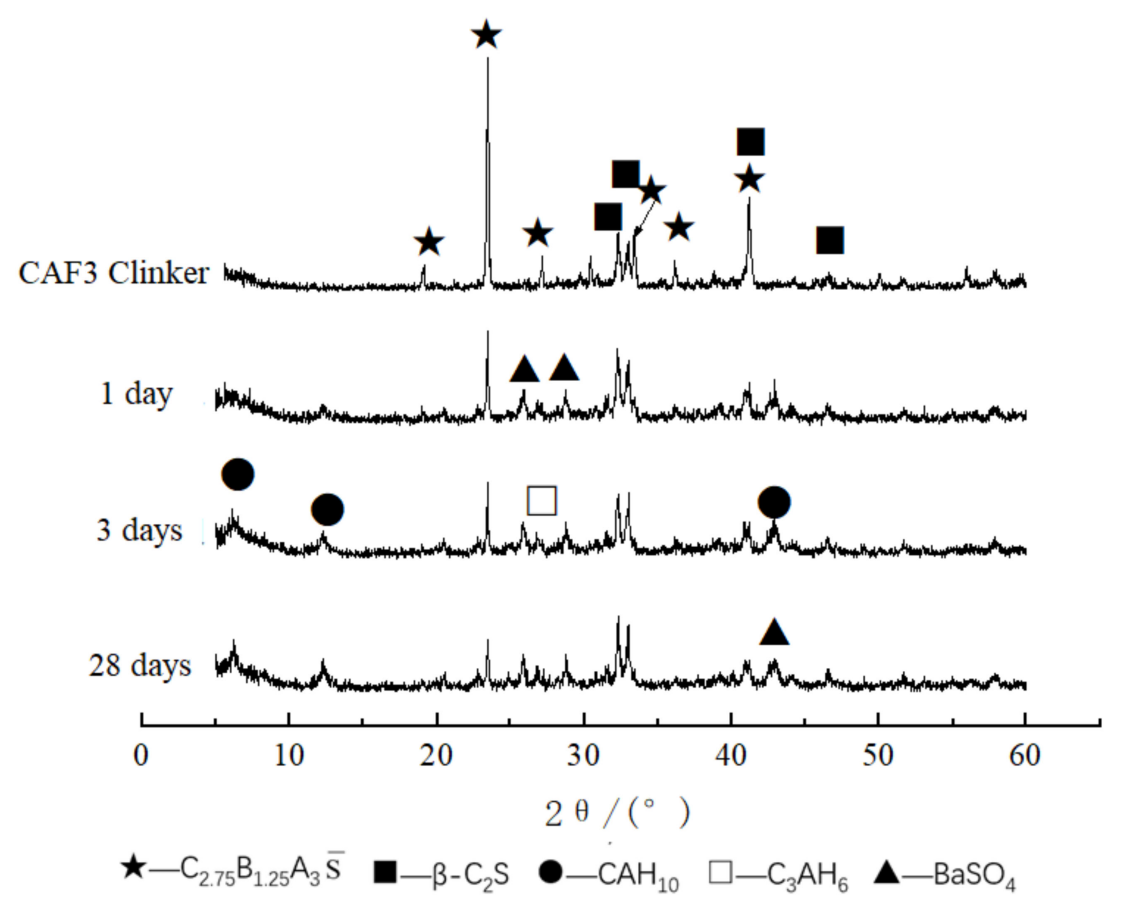

Figure 7. XRD patterns of CAF3 at different curing times.

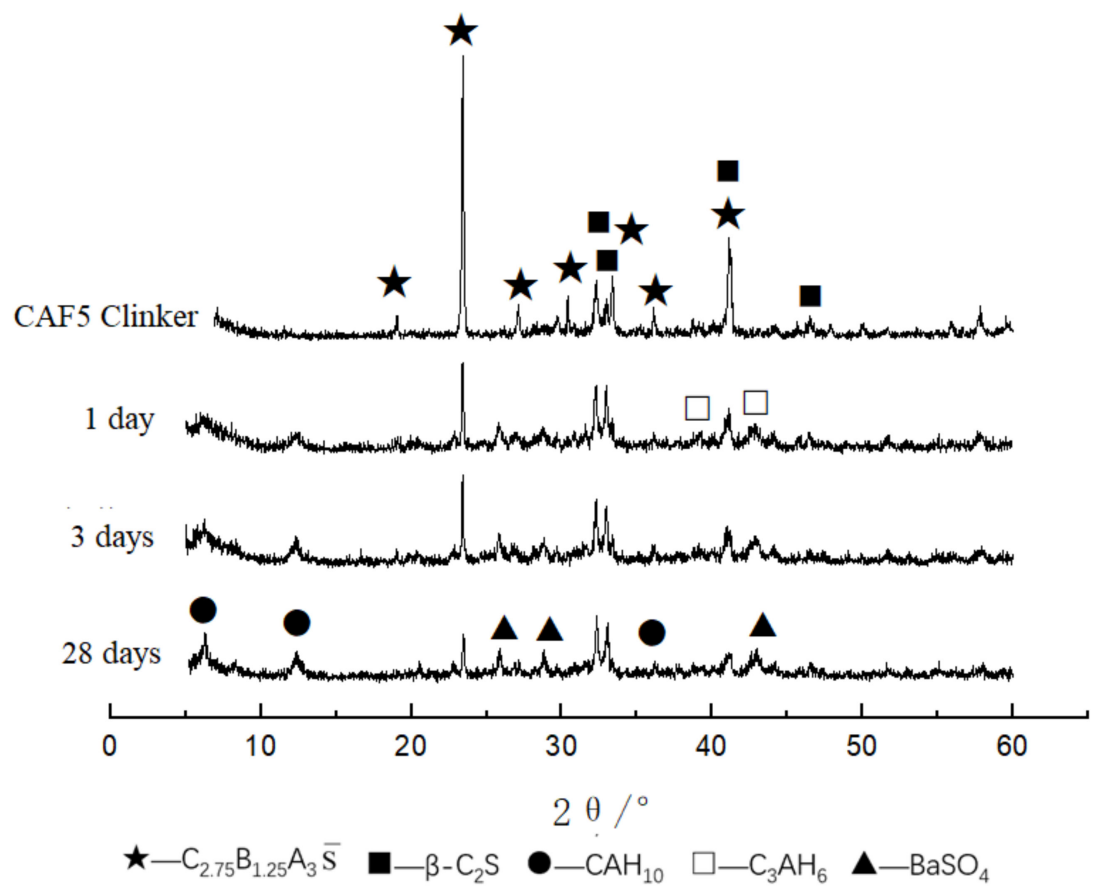

Figure 8. XRD patterns of CAF5 at different curing times. 


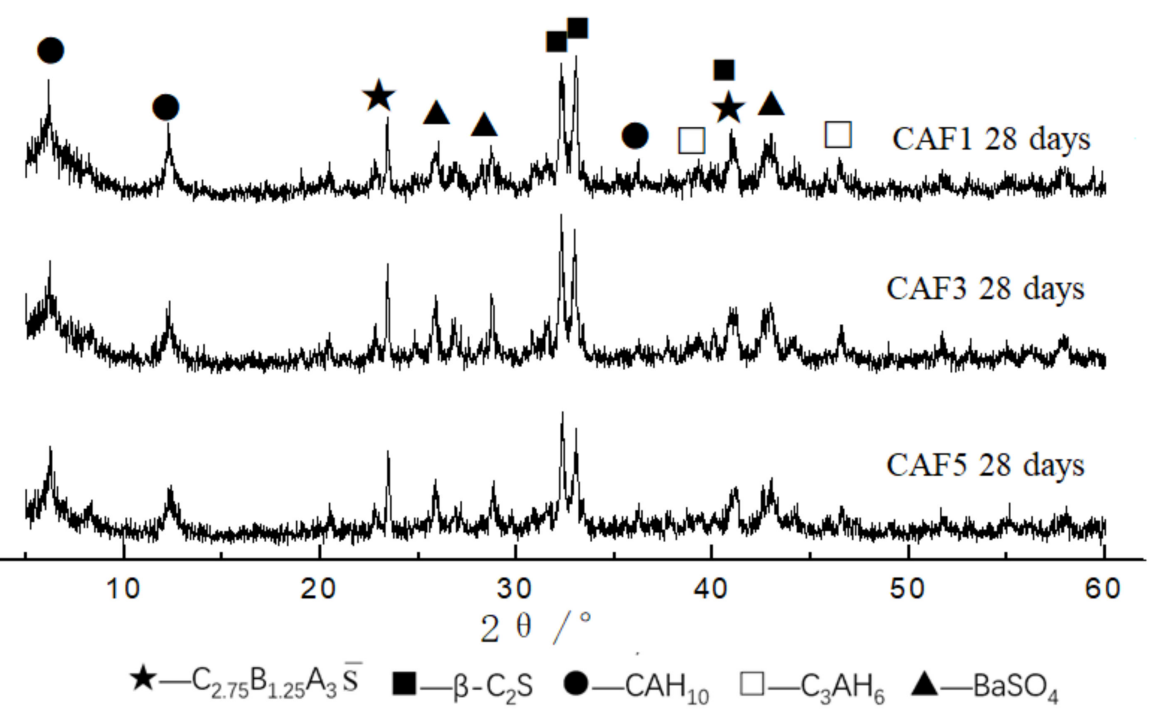

Figure 9. XRD patterns of different hydrated samples at 28 days.

\subsubsection{SEM Analysis of Hydration Samples}

The SEM images of the hydrated samples at different curing time sof CAF1, CAF3 and CAF5 are shown in Figures 10 and 11. It can be seen from Figure 10 that 1-point was mainly unhydrated $\mathrm{C}_{2} \mathrm{~S}$, and 2 and 3-points were hydrated barium calcium sulfoaluminate with the flocculation shape. From the SEM image of CAF5, it can be seen that most of the products were colloidal substances, which were a mixture of $\mathrm{AH}_{3}, \mathrm{BaSO}_{4}$ and $\mathrm{C}-\mathrm{S}-\mathrm{H}$ gels.

Combined with an XRD and SEM analysis, it was believed that the hydration process of the cement was roughly as follows:

$$
\begin{aligned}
\mathrm{C}_{2.75} \mathrm{~B}_{1.25} \mathrm{~A}_{3} \overline{\mathrm{S}}+\mathrm{H}_{2} \mathrm{O} & \rightarrow \mathrm{BaSO}_{4}+\mathrm{CAH}_{10}+\mathrm{AH}_{3} \\
\mathrm{C}_{2} \mathrm{~S}+\mathrm{H}_{2} \mathrm{O} & \rightarrow \mathrm{C}-\mathrm{S}-\mathrm{H}+\mathrm{CH}
\end{aligned}
$$

After $\mathrm{C}_{2.75} \mathrm{~B}_{1.25} \mathrm{~A}_{3} \overline{\mathrm{S}}$ was contacted with water, $\mathrm{BaSO}_{4}$ was formed firstly, and the remaining part combined with $\mathrm{H}_{2} \mathrm{O}$ and formed $\mathrm{CAH}_{10}$ and $\mathrm{AH}_{3}$. It also can be seen from the SEM that a large amount of colloid covered around the $\mathrm{CAH}_{10}$ and the unhydrated clinker. It was found that some microcracks are common features of the different samples. This is a very common experimental phenomenon. Therefore, from the XRD patterns, the diffraction peak of $\mathrm{C}_{2.75} \mathrm{~B}_{1.25} \mathrm{~A}_{3} \overline{\mathrm{S}}$ still appeared.

In summary, we believe that the main hydration products were $\mathrm{BaSO}_{4}, \mathrm{CAH}_{10}, \mathrm{AH}_{3}$ and $\mathrm{C}-\mathrm{S}-\mathrm{H}$ gels. The colloidal substance was filled in the crystal framework and the structure was dense. Therefore, the cement had high compressive strength. 

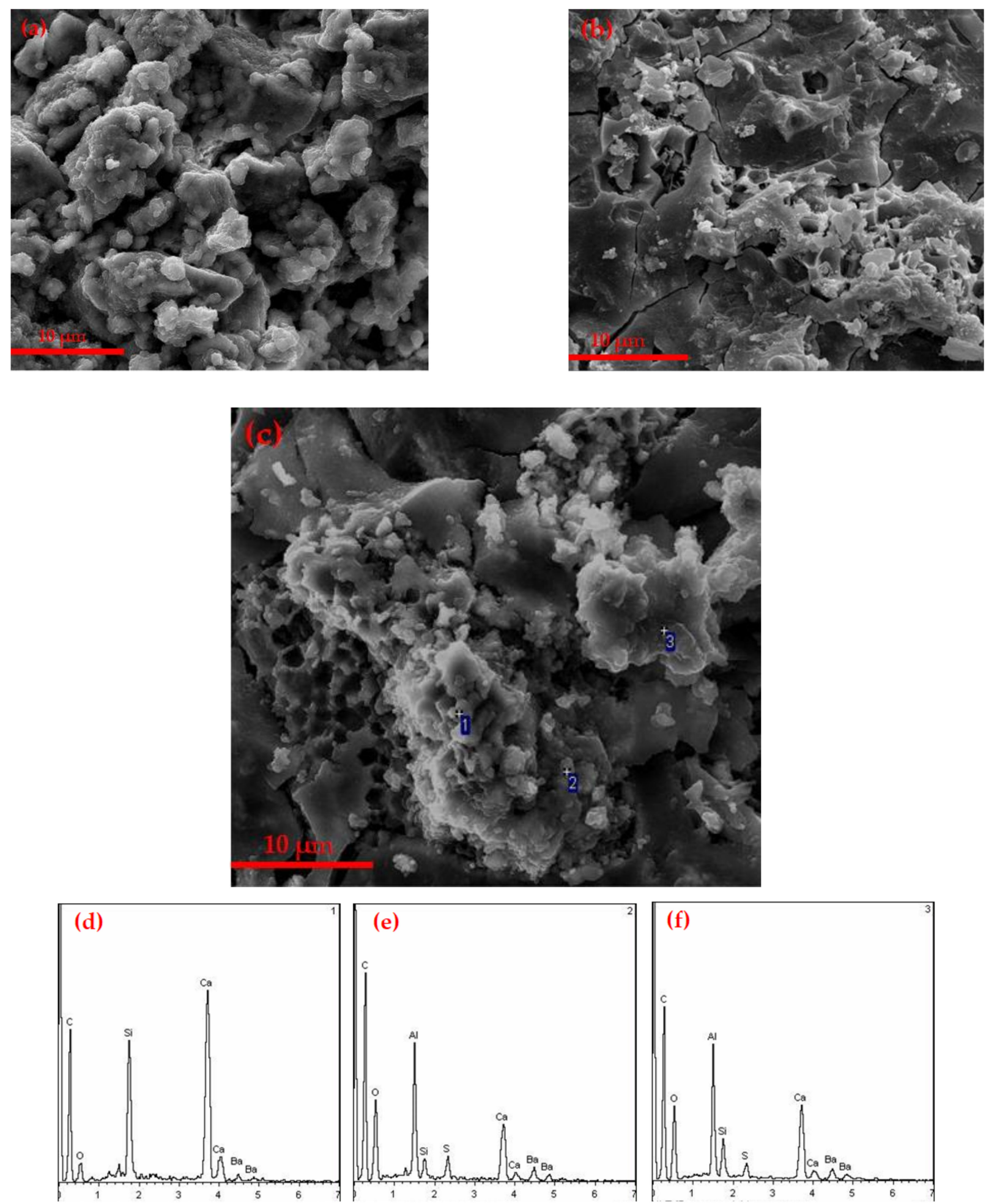

Figure 10. SEM of the (a-c) different $\mathrm{C}_{4} \mathrm{AF}$ contents of the clinker hydrated at 3 days, (d) 1-EDS, (e) 2-EDS, (f) 3-EDS. 

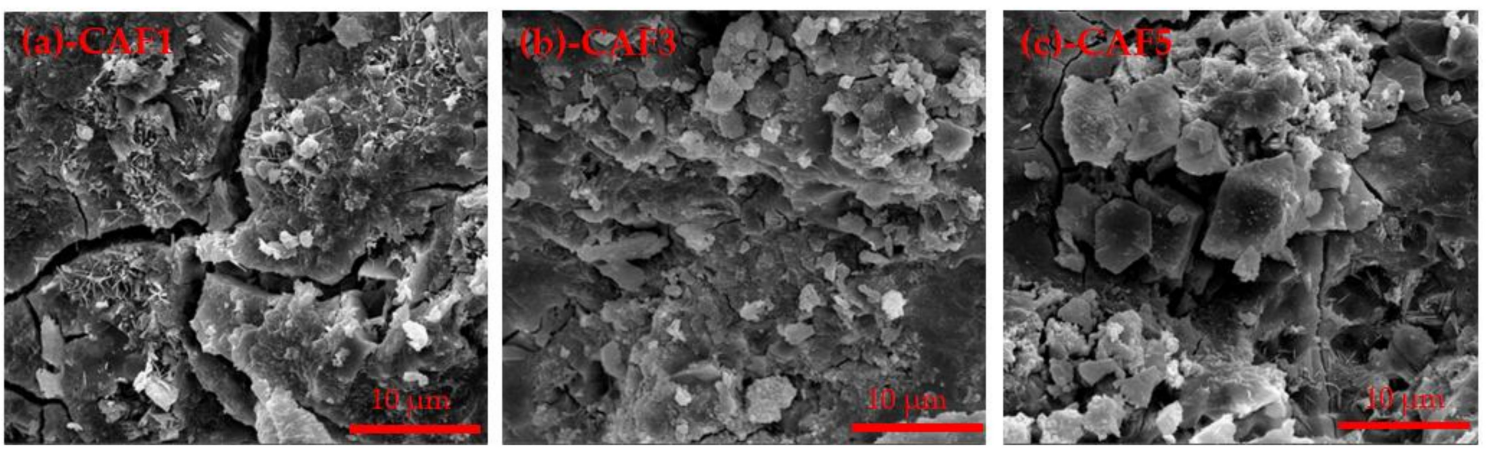

Figure 11. SEM of the different $\mathrm{C}_{4} \mathrm{AF}$ contents of the clinker hydrated at 3 days, (a)-CAF1, (b)-CAF3, (c)-CAF5.

\subsection{Effect of $\mathrm{C}_{2} F$ Content on Barium Calcium Sulfoaluminate Cement}

\subsubsection{Mechanical Properties}

The change of compressive strength at each curing age is shown in Figure 12 and Table 3. It can be seen from Figure 12 that the compressive strength of the clinker fluctuated greatly. In the range of $1-5 \%$, with the increased $\mathrm{C}_{2} \mathrm{~F}$ content, the compressive strength was not changed significantly, and the compressive strength was better. When the $\mathrm{C}_{2} \mathrm{~F}$ content was more than $7 \%$, the compressive strength showed a downward trend. This may be caused by calcination at $1350{ }^{\circ} \mathrm{C}$. The eutectic point of the system was lowered, and the minerals of the system were decomposed.

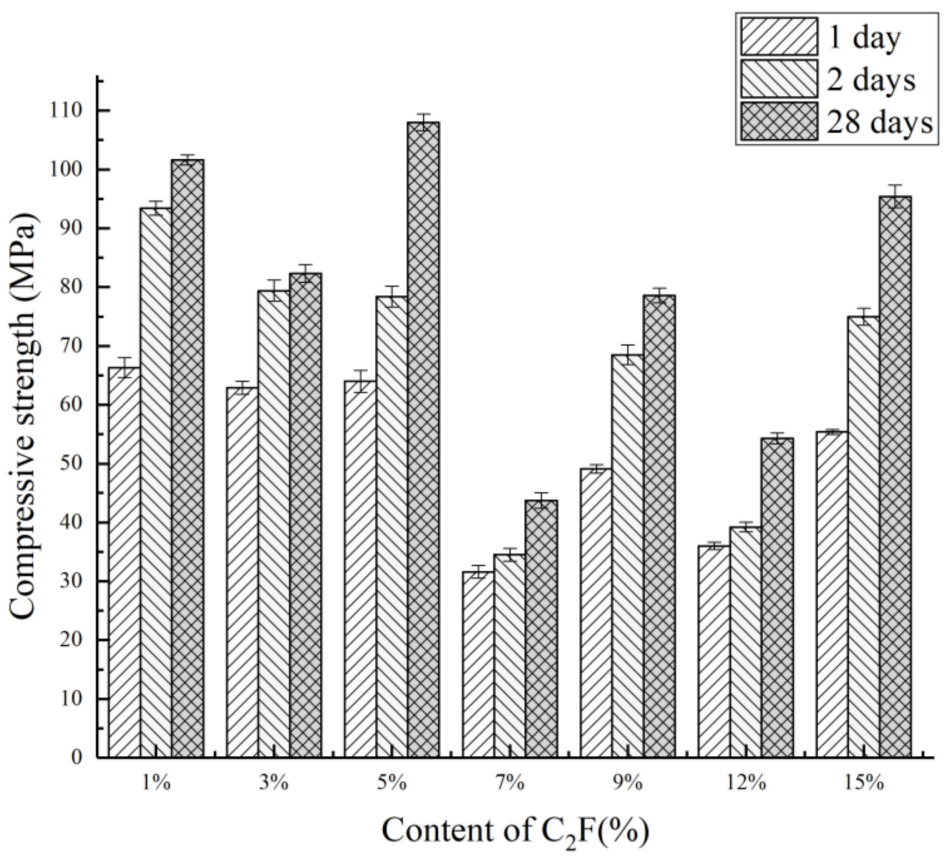

Figure 12. Compressive strength of the clinker at $1350^{\circ} \mathrm{C}$. 
Table 3. Compressive strength of clinker at $1350{ }^{\circ} \mathrm{C}$.

\begin{tabular}{ccccccc}
\hline \multirow{2}{*}{ Number } & \multicolumn{2}{c}{ The Content of Mineral Composition/\% } & \multicolumn{3}{c}{ Compressive Strength/Mpa } \\
& $\mathbf{C}_{\mathbf{2 . 7 5}} \mathbf{B a}_{\mathbf{1 . 2 5}} \mathbf{A}_{\mathbf{3}} \overline{\mathbf{S}}$ & $\mathbf{C}_{\mathbf{2}} \mathbf{S}$ & $\mathbf{C}_{\mathbf{2}} \mathbf{F}$ & $\mathbf{1}$ Day & 3 Days & 28 Days \\
\hline CF1 & 60 & 39 & 1 & 66.3 & 93.4 & 101.6 \\
CF2 & 60 & 37 & 3 & 62.9 & 79.4 & 82.3 \\
CF3 & 60 & 35 & 5 & 64.0 & 78.4 & 108.0 \\
CF4 & 60 & 33 & 7 & 31.6 & 34.5 & 43.7 \\
CF5 & 60 & 31 & 9 & 49.1 & 68.5 & 78.6 \\
CF6 & 60 & 28 & 12 & 36.0 & 39.2 & 54.3 \\
CF7 & 60 & 25 & 15 & 55.4 & 75.0 & 95.4 \\
\hline
\end{tabular}

\subsubsection{XRD and SEM Analysis of Clinker}

The X-ray diffraction analysis of the CF1, CF3 and CF5 clinkers was carried out with the D8-ADVANCE X-ray diffractometer (XRD), and the results are shown in Figure 13. It can be seen that the main minerals of the barium calcium sulfoaluminate cement clinker were $C_{2.75} B_{1.25} A_{3} \bar{S}$ and $\beta-C_{2} S$, and there was still a certain content of iron phase in the clinker, but the content was lower. The diffraction peak coincided with the diffraction peak of $\mathrm{C}_{2} \mathrm{~S}$, so it was not easy to observe.

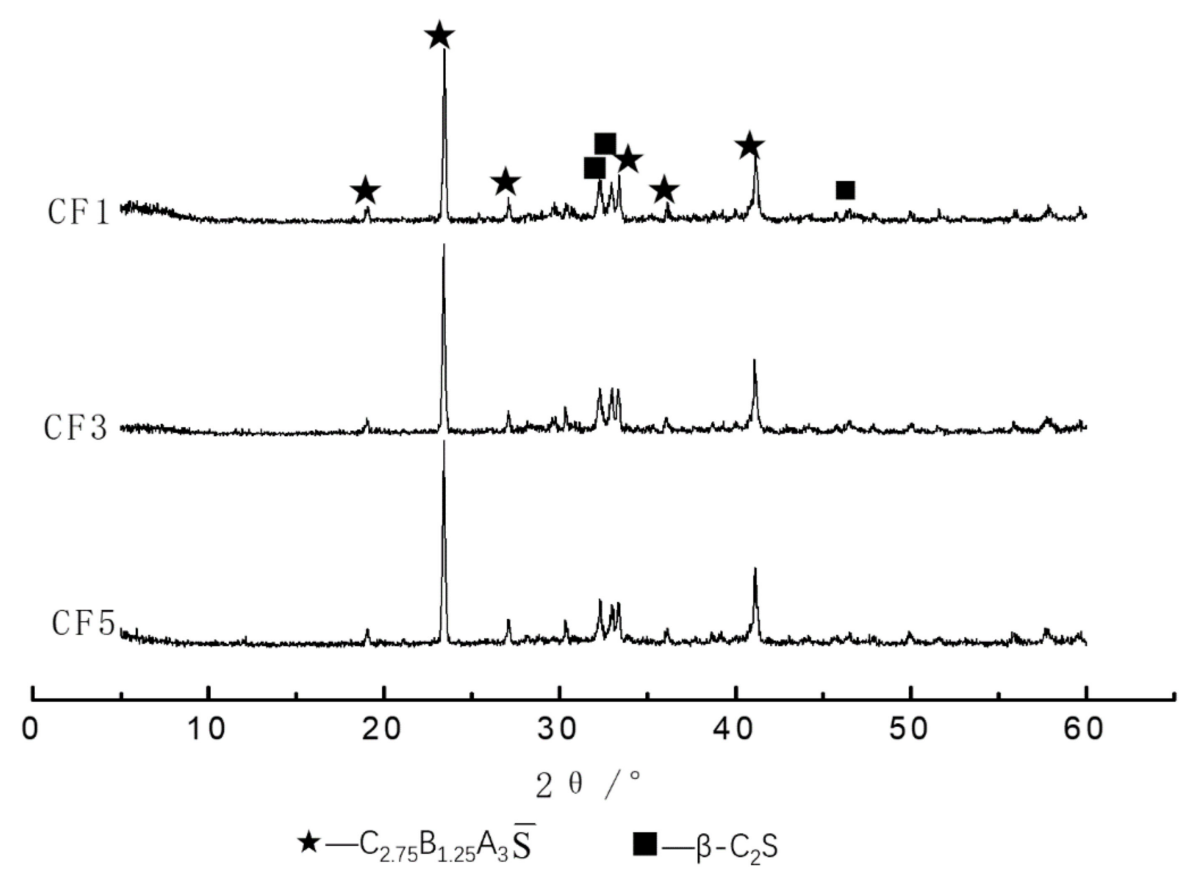

Figure 13. XRD patterns of different samples.

Figure 14 is the SEM-EDS image of the CF3 clinker mineral at $1350^{\circ} \mathrm{C}$. From Figure $14 \mathrm{a}$, there were a lot of small particles resembling a hexagonal plate-shaped rhombic dodecahedron, the particle size was uniform and the grain boundary was clear. From the SEM-EDS at point " 1 " in Figure 14b, it can be seen that the mineral at this point was barium calcium sulfoaluminate, and the size of the mineral was about $5 \mu \mathrm{m}$. At the same time, there were a lot of small egg-like particles observed; the SEM-EDS at point " 2 " in Figure 14b showed that the soft-grained clinker mineral was $\beta-C_{2} S$ with a size of more than $10 \mu \mathrm{m}$. It was observed that the periphery of the small particles was surrounded by the liquid phase. Combined with the XRD analysis in Figure 13, it can be determined that the barium calcium sulfoaluminate mineral was well developed. 

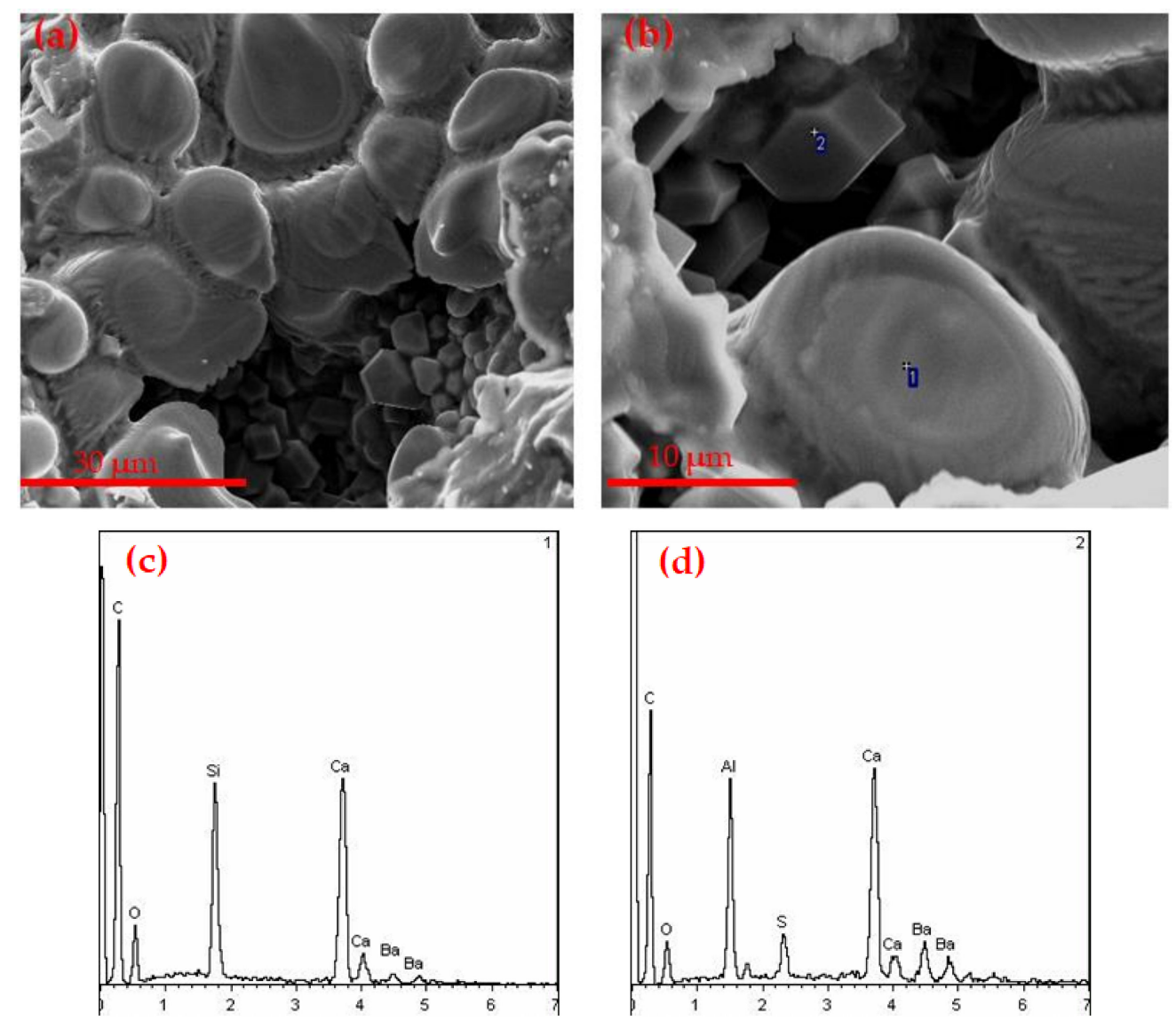

Figure 14. (a,b) SEM-EDS of CF3 clinker at $1350{ }^{\circ} \mathrm{C}$, (c) 1-EDS, (d) 2-EDS.

\subsubsection{XRD and SEM Analysis of Hydrated Samples}

The results of the XRD analysis of the hydration products of the CF1 clinker at various ages are shown in Figure 15. It can be seen that the hydration rate of the barium calcium sulfoaluminate mineral was very fast, and the hydration products were mainly $\mathrm{BaSO}_{4}$, $\mathrm{CAH}_{10}$ and $\mathrm{C}_{3} \mathrm{AH}_{6}$. In addition, there were some unhydrated $\mathrm{C}_{2.75} \mathrm{~B}_{1.25} \mathrm{~A}_{3} \overline{\mathrm{S}}$, and the unhydrated $\mathrm{C}_{2.75} \mathrm{~B}_{1.25} \mathrm{~A}_{3} \overline{\mathrm{S}}$ diffraction peaks were relatively higher at $1 \mathrm{~d}$ and $3 \mathrm{~d}$. The diffraction peaks of $\mathrm{CAH}_{10}$ gradually increased from 1,3 and 28 days.

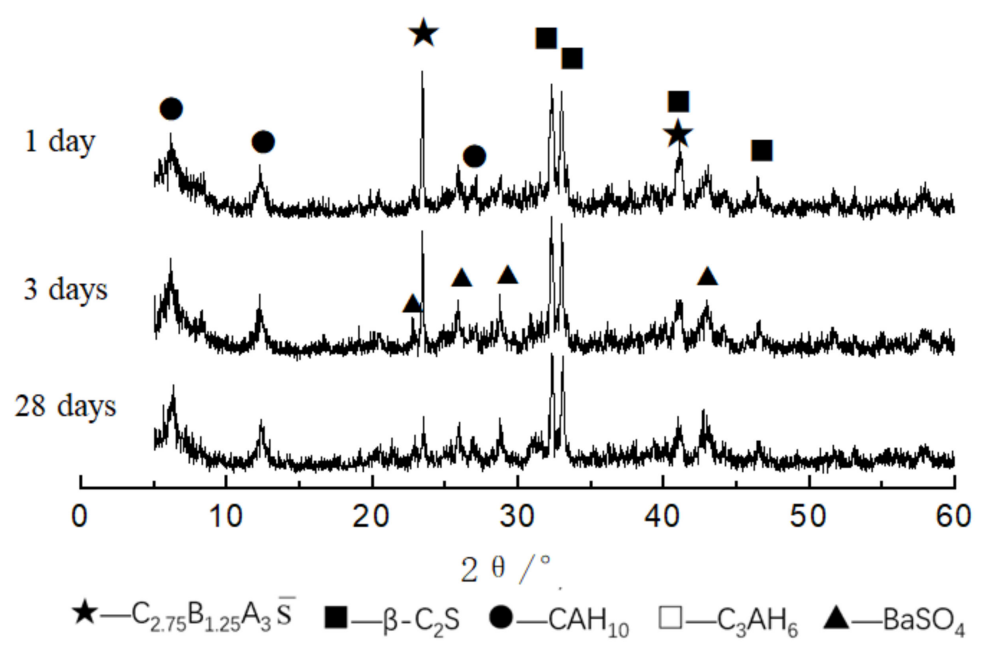

Figure 15. XRD patterns of sample CF1 at different hydrated days. 
Figure 16 shows the $\mathrm{XRD}$ patterns of $\mathrm{CF} 3$ at different curing ages. It can be seen that the main hydration products were $\mathrm{BaSO}_{4}, \mathrm{CAH}_{10}$ and $\mathrm{C}-\mathrm{S}-\mathrm{H}$ gels. It can be seen that the diffraction peak of $\mathrm{C}_{2.75} \mathrm{~B}_{1.25} \mathrm{~A}_{3} \overline{\mathrm{S}}$ decreased with the increased curing time. The diffraction peak of $\beta-C_{2} S$ decreased with the increased curing time, but the decreased trend was not obvious, indicating that the hydration speed of $\beta-C_{2} S$ was relatively slow. With the increased hydration time, the characteristic peak of $\mathrm{CAH}_{10}$ increased from 1 day to 28 days.

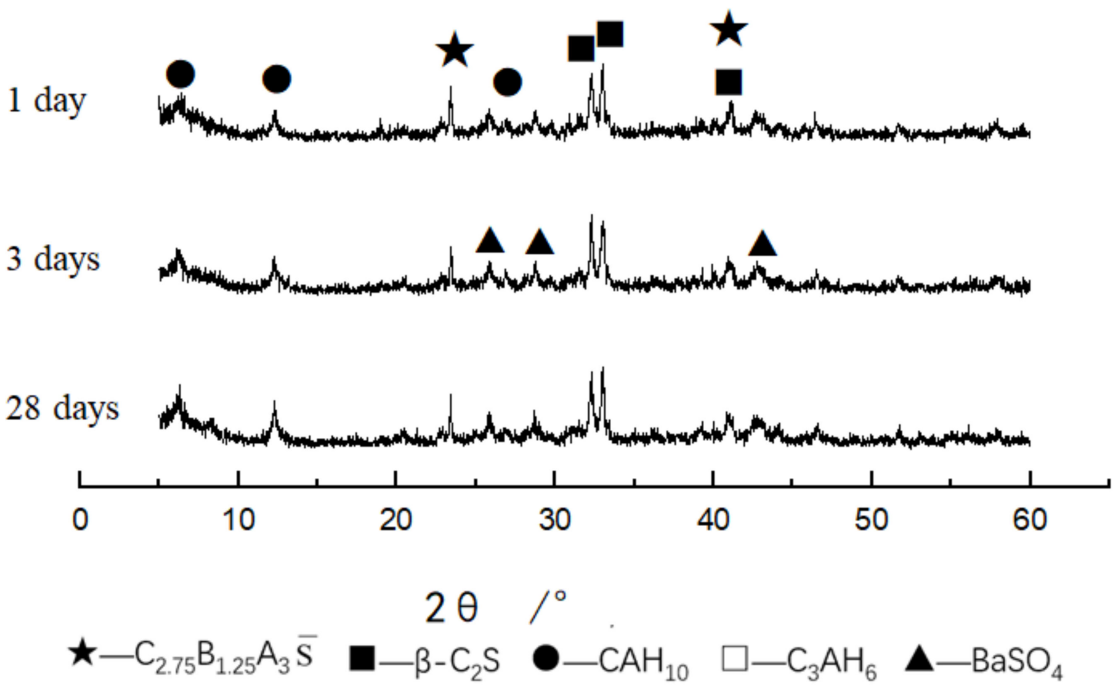

Figure 16. $\mathrm{XRD}$ patterns of sample $\mathrm{CF} 3$ at different hydrated days.

Figure 17 shows the XRD patterns of CF5 hydrated samples at different curing ages. It can be seen that the main hydration products were $\mathrm{BaSO}_{4}, \mathrm{CAH}_{10}$ and $\mathrm{C}_{3} \mathrm{AH}_{6}$. The diffraction peak of $\mathrm{CAH}_{10}$ from 1 day to 28 days increased. In addition, there were some unhydrated $\mathrm{C}_{2.75} \mathrm{~B}_{1.25} \mathrm{~A}_{3} \overline{\mathrm{S}}$. The diffraction peak containing $\mathrm{C}_{2.75} \mathrm{~B}_{1.25} \mathrm{~A}_{3} \overline{\mathrm{S}}$ decreased rapidly with the increased curing time. The diffraction peak of $\beta-\mathrm{C}_{2} \mathrm{~S}$ decreased with the increased curing time, but the degree of decrease was not obvious, indicating that the hydration speed of $\beta-C_{2} S$ was relatively slow.

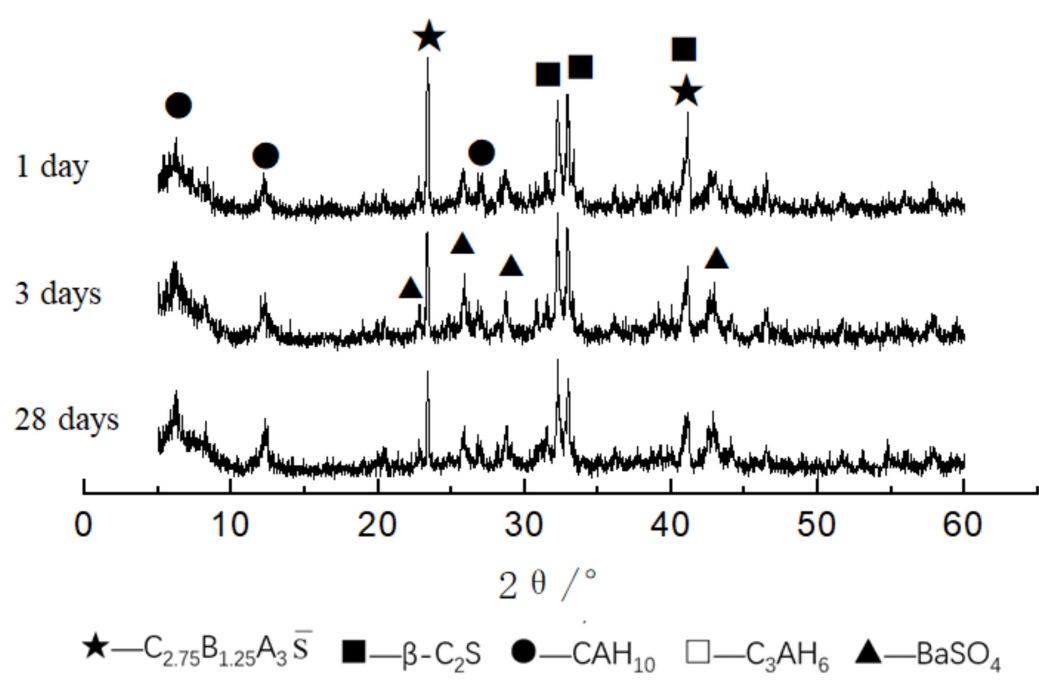

Figure 17. XRD patterns of sample CF5 at different hydrated days.

It can be seen from Figure 18 that the main hydration products were $\mathrm{BaSO}_{4}, \mathrm{CAH}_{10}$, the unhydrated barium calcium sulfoaluminate and $\beta-C_{2} S$. As shown in Figure 19, it can 
be seen that the hydration product after curing for 1 day was flocculent hydrated barium calcium sulfoaluminate, the structure was dense and the grain boundary of the cement became blurred, which explained the reason why the CF3 sample after curing for $1 \mathrm{~d}$ had the higher strength. After curing for 3 days, there were a lot of hydration products, which were hexagonal plates. The hydration products greatly increased and filled the pores, and the density of the cement paste increased. These were the reasons for the obvious increase in the 3 days compressive strength of the cement paste.

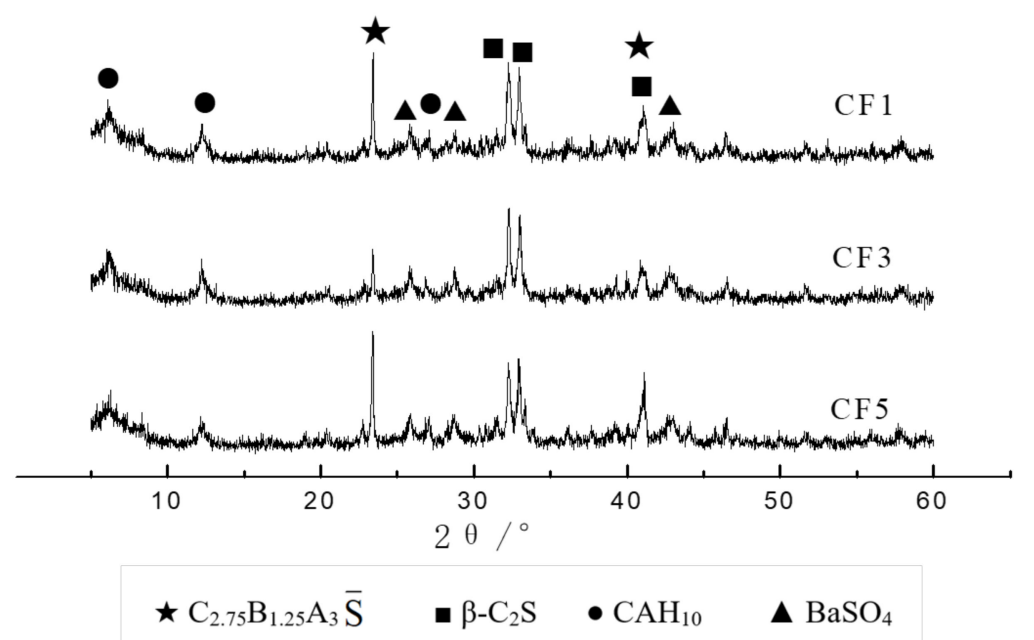

Figure 18. XRD of different samples at hydrated 1 day.
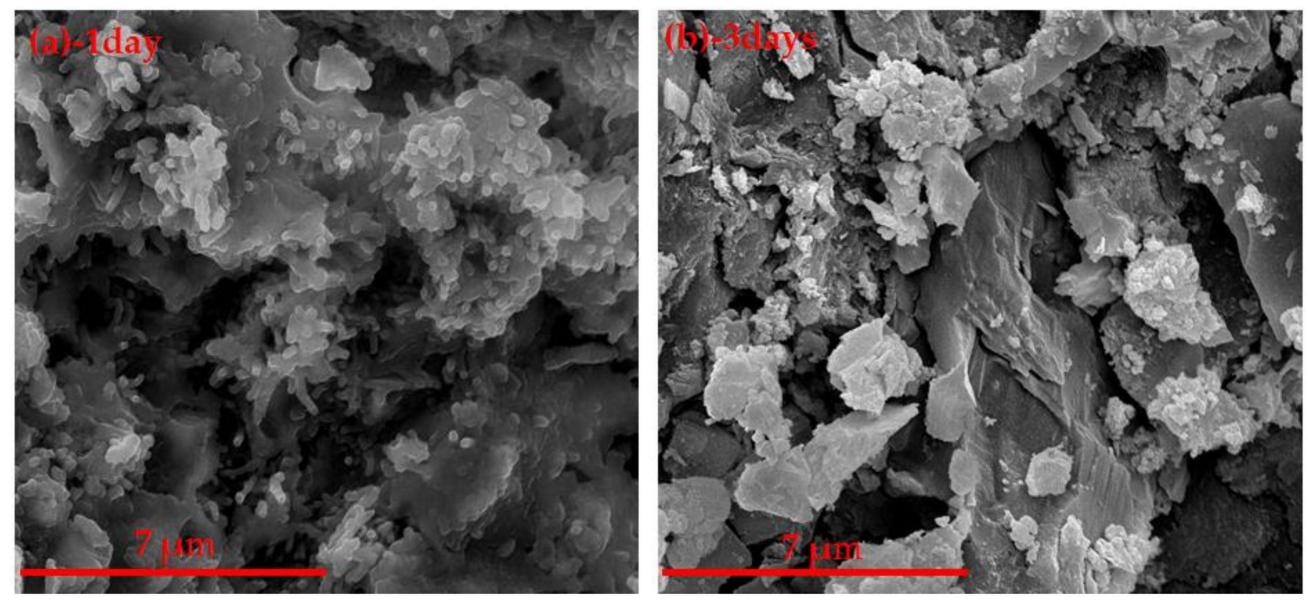

Figure 19. SEM of CF3 hydration paste, (a) 1 day, (b) 3 days.

Combined with the XRD and SEM analysis, it is believed that the hydration process of the cement was roughly as follows:

$$
\begin{aligned}
\mathrm{C}_{2.75} \mathrm{~B}_{1.25} \mathrm{~A}_{3} \overline{\mathrm{S}}+\mathrm{H}_{2} \mathrm{O} & \rightarrow \mathrm{BaSO}_{4}+\mathrm{CAH}_{10}+\mathrm{AH}_{3} \\
\mathrm{C}_{2} \mathrm{~S}+\mathrm{H}_{2} \mathrm{O} & \rightarrow \mathrm{C}-\mathrm{S}-\mathrm{H}+\mathrm{CH}
\end{aligned}
$$

After $\mathrm{C}_{2.75} \mathrm{~B}_{1.25} \mathrm{~A}_{3} \overline{\mathrm{S}}$ reacted with water, $\mathrm{BaSO}_{4}, \mathrm{CAH}_{10}$ and $\mathrm{AH}_{3}$ were formed. It can also be seen from SEM that a large amount of colloid covered the hydrated product $\mathrm{CAH}_{10}$ and the unhydrated clinker. Therefore, the diffraction peak of $\mathrm{C}_{2.75} \mathrm{~B}_{1.25} \mathrm{~A}_{3} \overline{\mathrm{S}}\left(2 \theta=24^{\circ}\right.$ and $41^{\circ}$ ) was still detected in XRD. In summary, we believe that the main hydration products were $\mathrm{BaSO}_{4}, \mathrm{CAH}_{10}, \mathrm{AH}_{3}$ and $\mathrm{C}-\mathrm{S}-\mathrm{H}$ gels. The structure was dense and the grain boundary of the cement became blurred. After curing for 3 days, the hydration products 
greatly increased and filled the pores, and the density of the cement paste was increased. The colloidal substance was filled in the crystal framework and the structure was dense. Therefore, the cement had high compressive strength.

\section{Conclusions}

This paper uses chemical reagents to burn calcium barium sulfoaluminate under laboratory conditions. The effects of different iron phases on the calcination and properties of barium calcium sulfoaluminate cement were studied. Combined with the XRD and the SEM-EDS analysis, the microstructure and composition of the barium calcium sulfoaluminate cement clinker and hydration samples were analyzed and characterized, and the following conclusions were drawn.

When the content of the iron phase increased, the compressive strength was decreased. While, when the content of $\mathrm{C}_{4} \mathrm{AF}$ was $15 \%$, the samples exhibited better properties. The compressive strengths after curing for 1,3 and 28 days were $74.3 \mathrm{MPa}, 76.2 \mathrm{MPa}$ and 102.5 $\mathrm{MPa}$, respectively. A proper amount of the iron phase can reduce the eutectic point of the sintered mature material system, increase the amount of liquid phase, reduce the viscosity of the liquid phase, effectively accelerate the migration of mineral ions and promote the formation and growth of minerals. When the iron phase composition was $\mathrm{C}_{4} \mathrm{AF}$ and the iron phase content was $5 \%$, the early hydration and later strength were better and the compressive strengths after curing for 1,3 and 28 days were $73.2 \mathrm{MPa}, 97.9 \mathrm{MPa}$ and 106.9 $\mathrm{MPa}$, respectively.

The composition and morphology of the mineral can be seen from the SEM-EDS. The oval-shaped particles were $C_{2} S$ minerals, the hexagonal plate-shaped or rhombohedral dodecahedral particles were barium calcium sulfoaluminate minerals and the iron phase was filled in between the two as solvent minerals. When the content of the iron phase was low, the liquid phase was low and the grain boundaries between particles were blurred, which was not conducive to the growth of minerals; when the content of the iron phase was higher, the eutectic point of the system decreased, and the clinker minerals melted at the same calcination temperature. A proper amount of iron phase was beneficial for the formation and growth of clinker minerals, the crystals were well developed and the grain boundaries were clear.

Author Contributions: Conceptualization, J.C., Y.Y., and K.C.; methodology, J.Z., and Y.Y.; validation, K.C.; formal analysis, J.Z.; investigation, J.Z.; resources, J.C., and K.C.; data duration, Y.Y.; writingoriginal draft preparation, J.C., J.Z., Y.Y., and K.C.; writing-review and editing, J.C., K.C., and J.Z.; visualization, K.C.; supervision, J.C., and K.C.; project administration, J.C.; funding acquisition, J.C. All authors have read and agreed to the published version of the manuscript.

Funding: This work was funded by National Natural Science Foundation of China No. 52172015, International Collaboration and Exchange Program from the NSFC-RCUK/EPSRC, No. 51761135011, DUT basic scientific research funding, No. DUT21ZD201.

Institutional Review Board Statement: Not Applicable.

Informed Consent Statement: Not Applicable.

Data Availability Statement: The data presented in this study are available on request from the corresponding author.

Conflicts of Interest: The authors declare no conflict of interest.

\section{References}

1. Cheng, X.; Ye, Z.M.; Chang, J.; Lu, L.C. Repairing bridges in coastal area with Ba bearing sulfoaluminate cement. Key Eng. Mater. 2009, 787, 501-506. [CrossRef]

2. Huang, Y.; Wang, S.; Hou, P.; Chen, Y.; Gong, C.; Lu, L. Mechanisms and kinetics of the decomposition of calcium barium sulfoaluminate. J. Therm. Anal. Calorim. 2014, 119, 1731-1737. [CrossRef]

3. Yu, J.C.; Qian, J.S.; Tang, J.Y.; Fan, Y.R. Effect of ettringite seed crystals on the properties of calcium sulfoaluminate cement. Constr. Build. Mater. 2019, 207, 249-257. [CrossRef] 
4. Chenchen, G.; Jibao, X.; Shoude, W.; Lingchao, L. Hydrating characteristics of modified Portland with Ba-bearing sulfoaluminate minerals. Ceram. Silik. 2016, 60, 12-18. [CrossRef]

5. Liu, B.; Wang, S.; Chen, Y.; Gong, C.; Lu, L. Effect of waste gypsum on the setting and early mechanical properties of belite$\mathrm{C}_{2.75} \mathrm{~B}_{1.25} \mathrm{~A}_{3}$ \$ cement. J. Therm. Anal. Calorim. 2016, 125, 75-83. [CrossRef]

6. Chang, J.; Xin, C. Influence of fluorite on the Ba-bearing sulfoaluminate cement. J. Shandong Inst. Build. Mater. 2001, 31, 213-216. [CrossRef]

7. Wang, Q. Inorganic non-metallic materials technology; China Building Materials Industry Press: Beijing, China, $2005 ;$ pp. 50-51.

8. Zhu, M. Experimental Research on Iron Phase Formation and Hydration. Cem. Eng. 1996, 6, 14-15.

9. Wang, Y.M. Sulfoaluminate cement; Beijing University of Technology Press: Beijing, China, 1996; pp. 86-102.

10. Guo, Y. Study on the formation mechanism of iron phases in ferro-aluminate cement. J. Chin. Ceram. Soc. 1988, 16, 481-488.

11. Huang, Y. Study on isothermal formation dynamics of calcium barium sulphaoluminate mineral. J. Inorg. Organomet. Polym. Mater. 2013, 23, 1172-1176. [CrossRef]

12. Li, Y.J. Study on the effect of $\mathrm{Fe}_{2} \mathrm{O}_{3}$ on the formation of alite sulfoaluminate cement clinker mineral. Cement 2000, 4, 5-7.

13. Cheng, X.; Chang, J. Study of Ba-bearing calcium sulfoaluminate minerals and cement. Cem. Concr. Res. 2000, 30, 77-81. [CrossRef]

14. Cheng, X.; Chang, J. Study on the hydration of Ba-bearing calcium sulfoaluminate in the presence of gypsum. Cem. Concr. Res. 2004, 34, 2009-2013.

15. Wang, S.; Huang, Y.; Gong, C.; Fu, X.; Lu, L. Formation and early hydration characteristics of $\mathrm{C}_{2.75} \mathrm{~B}_{1.25} \mathrm{~A}_{3} \$$ in binary system of $\mathrm{C}_{2.75} \mathrm{~B}_{1.25} \mathrm{~A}_{3} \$-\mathrm{C}_{2} \mathrm{~S}$. Constr. Mater. 2016, 66. [CrossRef]

16. Wang, S.; Huang, Y.; Gong, C.; Lu, L.; Cheng, X. Formation mechanism of barium calcium sulfoaluminate mineral. Adv. Cem. Res. 2014, 26, 169-176. [CrossRef]

17. Zhang, G. Effect of sulfoaluminate cement on the strength and water stability of magnesium potassium phosphate cement. Constr Build. Mater. 2017, 132, 335-342. [CrossRef]

18. García-Maté, M.; Londono-Zuluaga, D.; de la Torre, A.G.; Losilla, E.R.; Cabeza, A.; Aranda, M.A.G.; Santacruz, I. Tailored setting times with high compressive strengths in bassanite calcium sulfoaluminate eco-cements. Cem. Concr. Compos. 2016, 72, 39-47. [CrossRef]

19. Hargis, C.W. Early age hydration of calcium sulfoaluminate in the presence of gypsum and varying amounts of calcium hydroxide. Cem. Concr. Compos. 2013, 48, 105-115. [CrossRef]

20. Garcia-Mate, M. Rheological and hydration characterization of calcium sullfoaluminate cement pastes. Cem. Concr. Compos. 2012, 34, 684-691. [CrossRef]

21. Hargis, C.W. Calcium sulfoaluminate hydration in the presence of gypsum, calcite, and vaterite. Cem. Concr. Compos. 2014, 65, 15-20. [CrossRef]

22. Zhao, J.; Chang, J. Kinetic Analysis for Formation Process of Sr-Bearing Ye'elimite. J. Inorg. Organomet. Polym. Mater. 2017, 27, 1861-1869. [CrossRef]

23. Chang, J.; Li, J.; Han, J.; Zhang, T. Traces of $\mathrm{CH}$ in a $\mathrm{C}_{4} \mathrm{~A}_{3} \$-\mathrm{C}_{2} \mathrm{~S}$ hydration system. Constr. Build. Mater. 2019, 197, 641-651. [CrossRef]

24. Li, X.; Zhang, Y.; Shen, X.; Wang, Q.; Pan, Z. Kinetics of calcium sulfoaluminate formation from tricalcium aluminate, calcium sulfate and calcium oxide. Cem. Concr. Res. 2014, 55, 79-87. [CrossRef]

25. Chang, J.; Zhang, Y.; Shang, X.; Zhao, J.; Yu, X. Effects of amorphous $\mathrm{AH}_{3}$ phase on mechanical properties and hydration process of $\mathrm{C}_{4} \mathrm{~A}_{3} \mathrm{~S}^{-}-\mathrm{CS}^{-} \mathrm{H}_{2}-\mathrm{CH}-\mathrm{H}_{2} \mathrm{O}$ system. Constr. Build. Mater. 2017, 133, 314-322. [CrossRef]

26. Cuesta, A.; de la Torre, A.G.; Losilla, E.R.; Peterson, V.K.; Rejmak, P.; Ayuela, A.; Frontera, C.; Aranda, M.A. ChemInform Abstract: Structure, Atomistic Simulations, and Phase Transition of Stoichiometric Yeelimite. ChemInform 2013, 44, 1680-1687. [CrossRef]

27. Kurokawa, D.; Takeda, S.; Colas, M.; Asaka, T.; Thomas, P.; Fukuda, K. Phase transformation of $\mathrm{Ca}_{4}\left[\mathrm{Al}_{6} \mathrm{O}_{12}\right] \mathrm{SO}_{4}$ and its disordered crystal structure at 1073K. J. Solid State Chem. 2014, 215, 265-270. [CrossRef]

28. Feng, $X$. The structure and quantum chemistry studies of $3 \mathrm{CaO} \cdot 3 \mathrm{Al}_{2} \mathrm{O}_{3} \cdot \mathrm{SrSO}_{4}$. Cem. Concr. Res. 1996, 26, 955-962. [CrossRef]

29. Chang, J.; Shang, X.; Zhao, J. Study on Sintering System of Calcium Barium Sulfoaluminate by XRD Quantitative Analysis. Appl. Sci. 2015, 5, 989-997. [CrossRef]

30. Álvarez-Pinazo, G.; Cuesta, A.; García-Maté, M.; Santacruz, I.; Losilla, E.R.; de la Torre, A.G.; León-Reina, L.; Aranda, M.A.G. Rietveld quantitative phase analysis of Yeelimite-containing cements. Cem. Concr. Res. 2012, 42, 960-971. [CrossRef]

31. Cuesta, A.; Álvarez-Pinazo, G.; Sanfélix, S.G.; Peral, I.; Aranda, M.A.G.; de la Torre, A.G. Hydration mechanisms of two polymorphs of synthetic ye'elimite. Cem. Concr. Res. 2014, 63, 127-136. [CrossRef] 